\title{
A LIGA DAS NAÇÕES: Uma Perspectiva Europeia
}

\author{
Ana Letícia Sampaio ${ }^{1}$ e Gabriela Russo ${ }^{2}$
}

\begin{abstract}
Resumo
Neste artigo, objetivamos analisar a negociação realizada durante Conferência de Paz de Paris, em 1919, enfatizando os procedimentos que deram origem à Liga das Nações. Pretendemos, assim, verificar a partir dos fatores presentes no processo decisório da própria Conferência, novos elementos que expliquem o fracasso da Organização décadas mais tarde. Dessa maneira, intenciona-se desconstruir o papel dos Estados Unidos, o qual consideramos supervalorizado dentro da situação abordada, enquanto trazemos à pauta a política externa de França e Reino Unido como uma nova perspectiva para entender o insucesso da Liga das Nações.
\end{abstract}

\section{Palavras Chave}

Liga das Nações - Política Externa - Conferência de Paz de Paris - França - Reino Unido.

\section{Abstract}

This article intends to analyse the Paris Peace Conference negotiations, in 1919, highlighting the talks that had the creation of the League of Nations as its main concern. Therefore, we aim to find out new elements during the decisionmaking process at the Conference that may assist us in the explanation about the Organization's failure decades later. Thus, we also plan to deconstruct the usual central role of United States in this context, once we consider it overrated, while we bring out the foreign policy of United Kingdom and France as an innovative perspective to understand the fate of the League of Nations.

\section{Key Words}

League of Nations - Foreign Policy - Paris Peace Conference - France - United Kingdom

\footnotetext{
${ }^{1}$ Ana Letícia Sampaio é graduanda em Relações Internacionais pela PUC-Rio.

${ }^{2}$ Gabriela Russo é graduanda em Relações Internacionais pela PUC-Rio.
} 


\section{Résumé}

Cet article a comme objectif principal vérifier les pressions systémiques et la négociation au cours de la Conférence de Paix de Paris, en 1919, pour ainsi analyser la création et l'échec de la Société des Nations. À travers d'une perspective européenne et des éléments qu'existent dans le processus diplomatique, nous voulons expliquer le destin échoué de l'institution décennies plus tard. Afin d'atteindre ce propos nous élaborerons une hypothèse qui confère une relevance majeur du rôle de la politique étrangère de la France et du Royaume-Uni et discrédite le rôle toujours surestimé des États-Unis dans le système international dans la période analysée.

\section{Mots-clés}

Société des Nations - Politique Étrangère - Conférence de Paix de Paris - France Royaume-Uni 


\section{Introdução}

A Conferência de Paz de Paris (doravante, Conferência) foi, para muitos, o marco do século XX que deu fim à Grande Guerra e, finalmente, estabeleceu os fundamentos da paz para uma Europa unida e livre de conflitos, mediada pelo legalismo e institucionalização pioneira da Liga das Nações (doravante, Liga) e, paradoxalmente, pelas punições definidas no Tratado de Versalhes. Entretanto, o conflito estourado em 1939 mostrou que essa paz, em tese delineada pela Conferência, não foi tão efetiva quanto a almejada pelos peacemakers de 1919. Sendo assim, o momento da elaboração do Tratado de Versalhes era absolutamente ímpar na história, tendo em vista as proporções, também nunca antes vistas, que foram vislumbradas no conflito iniciado em 1914 (MacMillan, 2004, p.27-36).

Após tamanha destruição, era necessária a instauração de uma ordem internacional que evitasse a recorrência de um trauma tão intenso e de prejuízos tão grandes. Alguns Estados - principalmente os Estados Unidos - sustentavam o estabelecimento de uma nova ordem, cristalizada pelo conceito de seguraça coletiva presente no projeto da Liga, mas esses ideais freqüentemente se chocavam com os interesses de outros países, os quais visavam ao restabelecimento do status quo ante bellum, isto é, do antigo Concerto Europeu, especialmente devido à questão da segurança nacional que a todo o momento era ameaçada por conflitos periódicos (Mearsheimer, 1994/95, p.34-37).

O tema, portanto, mostra-se fundamental para as Relações Internacionais, pois o contexto abordado foi essencial para a formação da ordem internacional vigente na 
contemporaneidade. A Liga das Nações foi, inquestionavelmente, o precedente histórico e jurídico para a Organização das Nações Unidas (Herz \& Hoffmann, 2004, p.97) e, conseqüentemente, influenciou e moldou a dinâmica adotada por essa organização tão polêmica e debatida na atualidade. No entanto, embora a importância da Liga seja marcante e facilmente observável, sua criação, muitas vezes, é negligenciada ou subjugada pela literatura disponível.

É por esse motivo que pretendemos, neste artigo, abordar mais atentamente as negociações empreendidas pelas grandes potências “vencedoras” na Conferência de modo a relacionálas satisfatoriamente com a atuação e o fracasso da Liga. Adotaremos essa linha argumentativa, objetivando explicar o próprio processo de formação da instituição, limitado pelas pressões sistêmicas atuantes na diplomacia da época, em vez de atribuir esse evento a fatores exógenos e a conflitos desarticulados entre si, como muitos autores atribuem, desenvolvendo argumentos superficiais, sob nosso ponto de vista, que analisaremos mais extensamente a seguir.

Nesse âmbito, constatamos uma panóplia de obras referentes ao fracasso da Liga; todavia, nenhuma que aborde o viés que intencionamos, enfatizando o papel de França e Reino Unido no pós-guerra, tendo em vista o peso dessas delegações na Conferência de 1919 e a incapacidade e desinteresse estadunidenses de manter a instituição. Existem inúmeras construções teóricas sobre o fracasso da Liga, incontáveis conjecturas sobre fatos posteriores que levaram ao desmantelamento da instituição, contudo, não encontramos nenhuma que trate com atenção o contexto em que a Liga foi criada, os atores relevantes na 
ocasião e a maneira como cada um deles se portou em relação ao projeto wilsoniano. Portanto, selecionamos o material de pesquisa a partir do critério de adequação ao tema abordado, significância para a teoria de relações internacionais e aproximação à explicação que pretendemos corroborar.

Eric Hobsbawm (1994) é um dos muitos autores que correlacionam o fracasso da Liga ao comportamento dos Estados Unidos. A partir desse argumento principal, o autor afirma que a política de autodeterminação dos povos apresentada durante a Conferência pelo presidente Woodrow Wilson foi uma lástima, tendo em vista sua indefinição nacionalidade, territorialidade, religião, etnia, etc. - e o resultante desejo de separação de inúmeros povos que poderiam ter convivido pacificamente dentro de um mesmo território. Hobsbawn afirma com muita propriedade que estas regiões separadas no pós-I Guerra por meio de movimentos baseados na autodeterminação, posteriormente, entraram em conflitos aterradores. A situação empírica mais paradigmática para essa explanação, e que demonstra quão construtivo é esse ponto de vista, foi a ocorrida nos Bálcãs na década de 1990, que representa claramente o efeito desse tipo de política. (Hobsbawm, 1994, p. 39)

O autor trata, ainda, da grande influência do senado estadunidense ao recusar a ratificação do Pacto da Liga. Ele sustenta que uma organização que não possuísse um membro que se mostrava como a nova grande potência do sistema internacional estava fadada ao fracasso antes mesmo de ter iniciado suas competências. Além disso, Alemanha e a Rússia, por não estarem inseridas no contexto de segurança coletiva designado por Wilson, agiam independentemente no cenário europeu, tornando a Liga seria um mecanismo instável, uma 
vez que não abarcaria uma grande parte dos Estados centrais do sistema. (Hobsbawm, 1994, p.39-43)

\begin{abstract}
A abordagem de Hobsbawn (1994) é bastante pertinente, uma vez que pretende avaliar o sistema de Estados como um todo e definir as pressões que o integram. Entretanto, cabe questionar como a Alemanha e a Rússia agiriam de modo relevante no sistema, tendo em vista a incrível destruição que assolara ambos os países durante a Guerra, além, é claro, das reparações que pesavam contra a Alemanha e da instabilidade política da Rússia desde a Revolução de 1917.
\end{abstract}

Além disso, o status conferido aos Estados Unidos de “nova grande potência” é de fácil teorização sob uma perspectiva post facto. No entanto, cabe a problematização de até que ponto os norte-americanos, à época, já haviam assumido seu papel de líderes mundiais e de mantenedores do sistema de modo que sua ausência na organização representasse necessariamente seu insucesso.

Robert E. Riggs e Jack C. Plano são mais um exemplo de autores que abordam o processo de formação da Liga. Estes enumeram uma série de fatores como motivos para o fracasso da instituição, mas também não se atém àquestão da França e do Reino Unido. Apesar de os autores abordarem muito produtivamente o fato de que o fracasso não se deu exclusivamente devido à indeferência norte-americana, eles enumeram elementos como o “Caso da Manchúria” e o “Caso da Etiópia” (Riggs \& Plano, 1994, p. 6-9) como exemplos paradigmáticos para o fracasso do regime. Cabe-se questionar, nesse ponto, a excessiva 
importância que é atribuída a esses elementos desarticulados - que, de fato, a Liga não conseguiu solucionar - que, no entanto, não são os fatores mais profundos que determinaram o fatídico destino da organização.

Esses “casos” não explicam o fim precoce da Liga, uma vez que não abordam e estrutura de funcionamento da instituição e o processo decisório, moldado por interesses políticos, que levou à atuação prática sofrível da organização nas situações supracitadas. Sendo assim, a atuação ineficaz em si não é o elemento explicativo, mas sim os mecanismos formais que moldaram a liberdade de ação dos membros da Liga e que, sob a nossa perspectiva, foram criados com o intuito consciente de minar politicamente a importância da instituição, tendo em vista que ela era, no momento da negociação em 1919, apenas uma concessão que as potências europeias tiveram que fazer às demandas norte-americanas em troca de outros benefícios.

Nesse sentido, até mesmo o texto desses autores, que se pretendem abertos a novas perspectivas e que enumeraram várias justificativas ${ }^{3}$ compiladas no subtítulo sugestivo chamado de “Uma Autópsia”, ainda não conseguiram atingir a camada mais essencial da questão, que é a falta de hegemonias capazes de assegurar o funcionamento do regime e, dentre as que existiam, uma ainda estava em processo de consolidação - os Estados Unidos

\footnotetext{
${ }^{3}$ A incapacidade dos membros em cumprir os princípios estabelecidos no Pacto, dificuldades processuais ao longo do crescimento da Liga - como a questão de decisões unânimes em determinados órgãos -, a ausência dos Estados Unidos como membro da organização, a íntima relação com as cláusulas injustas entre a Liga e o Tratado de Versalhes, a simples insustentabilidade do conceito de segurança coletiva, etc. (Riggs e Plano, 1994, p. 10-11)
} 
- e as outras duas - Inglaterra e França - não tinham interesses, por diferentes motivos, de manter a ordem da maneira como ela tinha sido idealizada em Versalhes.

Nossa questão é, desse modo, averiguar como o embate existente entre a política externa de França e Reino Unido, levando em conta a plena racionalidade desses atores, contribuiu significativamente para o insucesso da Liga das Nações. A hipótese que pretendemos corroborar afirma que França e Reino Unido eram as duas únicas potências que poderiam garantir o bom funcionamento da instituição, tendo em vista o caráter ainda isolacionista norte-americano. Ademais, enfatizamos que a política externa de auto-ajuda praticada pelos Estados europeus vencedores, buscando o aumento de seu poder relativo e sua sobrevivência enquanto potências centrais do sistema, foram elementos fundamentais para que a Liga se tornasse apenas um instrumento de barganha em relação aos Estados Unidos durante as negociações.

Nossa hipótese inclui, ainda, que a política externa da França priorizava a contenção total da Alemanha com o objetivo maior de evitar futuras ameaças e prezava pelo aumento do poder relativo francês, de modo a assegurar sua permanência entre o grupo de Estados mais importantes do sistema internacional, fato que tinha sido seriamente ameaçado pelos anos de guerra e pela destruição na qual o território e a economia francesa se encontravam. A política externa do Reino Unido, por sua vez, zelava pela continuidade de seu império e, para tanto, pela manutenção de sua hegemonia naval e comercial, desejando, portanto, uma recuperação econômico-financeira de todos os países europeus com o intuito de voltar a lucrar com as trocas comerciais e retornar à Pax Britannica instituída anteriormente. 
Fica claro, então, que a Liga das Nações, como instituição, não foi capaz de alterar o comportamento auto-centrado dos Estados na busca de seus interesses primordiais e particulares. França e Reino Unido não relativizaram seus objetivos diplomáticos no processo de negociação na Conferência de Paris em prol da coletividade de Estados, mesmo tendo se comprometido com os termos da Liga, que defendiam ações mais orquestradas e um sistema internacional mais integrado e cooperativo. Sendo assim, a Liga das Nações não conseguiu garantir uma maior estabilidade política na Europa, nem influenciou ou alterou o comportamento de seus Estados-membros no que tange à atuação internacional.

Adotaremos o marco teórico neo-realista ofensivo de John J. Mearsheimer (1994/95), em sua obra The False Promise of International Institutions, que prega, além da sobrevivência como o interesse principal dos Estados, que eles vivem em um ambiente anárquico, sem uma autoridade supranacional com poder coercitivo; que os Estados podem ser nocivos uns aos outros devido a suas capacidades militares; que não se pode prever com certeza as intenções alheias nem confiar em previsões nesse âmbito; e que os Estados agem estrategicamente para sobreviver no sistema internacional. Nesse sentido, para este autor, os Estados se utilizam das instituições para aumentar o seu poder dentro do sistema e, portanto, a função de mediação de conflitos que a Liga se auto-atrubuía não deixava de ser uma estratégia para que os Estados alcançassem seus objetivos próprios (Mearsheimer, 1994/95, p. 8-10). 
É importante ressaltar que mencionaremos de maneira auxiliar a teoria da Estabilidade Hegemônica de Charles P. Kindleberger (1973) em sua obra The World in Depression para reafirmar a necessidade da existência de uma potência central para que a Liga pudesse funcionar satisfatoriamente, complementando a abordagem neo-realista de que os Estados instrumentalizam as instituições.

Quanto ao conteúdo metodológico do artigo, classificaremos a política externa da França e Inglaterra como variável dependente e as pressões sistêmicas presentes em 1919 como variáveis independentes. O recorte temporal será o período de negociações da Conferência, entre 19 de janeiro de 1919 e 16 de janeiro de 1920 (Enciclopédia Britânica, 2008). Entretanto, pretendemos nos referir de maneira substancial às consequências que consideramos diretamente provenientes dessas negociações, em especial, o fracasso da Liga, ocorrido de maneira inexorável na década de 30. O recorte geográfico, por sua vez, se limitará principalmente à Europa, mas não deixaremos de citar as colônias das grandes potências europeias na África e na Ásia que, mesmo não situadas no Velho Continente, influenciavam solidamente as relações de poder estabelecidas por lá.

Tendo em vista esses aspectos, não é difícil inferir que utilizaremos o nível de análise sistêmico para expor nosso raciocínio, já que foi a conjuntura internacional que limitou a maioria dos posicionamentos adotados na Conferência. Para desenvolver nossa hipótese, utilizaremos, primeiramente, o método comparativo para expor e analisar as políticas externas da França e da Inglaterra relativas à criação da Liga das Nações, no período delimitado da Conferência. Em seguida, empregaremos o método qualitativo para 
demonstrar como o interesse nacional das hegemonias minimamente interessadas em manter o regime, França e Reino Unido, gerou uma instituição vazia e sem aquiescência real de nenhuma dessas potências.

\section{A Política Externa da França}

Para demonstrar como a criação da Liga das Nações foi absolutamente contingente e proveniente de um projeto pessoal do chefe de Estado norte-americano, e que, com isso, não gozava da fundamental aquiescência de nenhuma potência à época - nem mesmo do próprio Estados Unidos - é necessário abordar um pouco do cálculo custo-benefício empreendido por França e Reino Unido durante as negociações em Paris.

O debate sobre a criação da Liga das Nações levantou opiniões divergentes entre as delegações presentes, principalmente da representação francesa, que, na maioria das sessões, se mostrava cética quanto ao projeto dos EUA. Para os representantes franceses, a punição alemã, em vez da criação de uma instituição internacional, deveria vir em primeiro lugar para que a Europa pudesse atingir uma paz justa e duradoura (Kergueno, s.d.). Nesse momento, então, a França se sentia ameaçada por uma possível reestruturação da Alemanha, especialmente no âmbito econômico-militar; e, uma vez que a necessidade de auto-defesa e a sobrevivência de um Estado são aspectos fundamentais para o governo e a nação de um território, os principais objetivos da diplomacia francesa nas negociações giravam primordialmente em torno da intimidação da Alemanha em vez da cooperação no 
sistema internacional, ainda que a França houvesse se comprometido com a criação da Liga.

A França, seguindo então uma lógica de self-help, queria estabelecer punições drásticas à Alemanha para que ela não pudesse se reconstruir e voltar a ser uma ameaça. Caso o Estado alemão se fortalecesse militar e economicamente mais uma vez, os franceses não teriam, ao contrário dos EUA e da Grã-Bretanha, capacidade para mover sua máquina de guerra, podendo gerar conseqüências lastimáveis a esse Estado. Tendo em vista que o interesse maior de todas as unidades do sistema internacional é, justamente, a sobrevivência associada à ampliação do seu poder, a questão alemã era um tema muito delicado e importante na política francesa deste momento (Mearsheimer, 1994/95, p. 9). Esse constrangimento sistêmico motivou a França a reivindicar, em sua política relativa à Liga, um exército internacional que ficaria disponível caso a Alemanha não cumprisse os termos do Tratado de Versalhes (Kissinger, 1994, p.228).

As premissas da segurança coletiva, segundo a qual os Estados devem abdicar do uso da força para resolução de conflitos, relativizar seus interesses nacionais em nome do bem comum e na noção de que os Estados devem confiar uns nos outros, (Mearsheimer, 1994/95, p. 26-30) nunca agradaram, de fato, os franceses. Porém, como Wilson era adepto desse princípio, advogando em prol da confiança e em detrimento da coerção, e como ele era um ator de absoluta relevância sob a perspectiva dos interesses franceses especialmente no âmbito econômico -, as discussões sobre o tema motivaram intensos debates entre esses dois Estados. Após algumas sessões exaustivas, o Reino Unido e os 
EUA cederam, prometendo que entrariam em guerra juntos caso a Alemanha se apresentasse novemente como um país agressor (Kissinger, 1994, p.236-240).

A França acabou por concordar com a criação da Liga das Nações nas linhas gerais alinhavadas por Wilson, uma vez que os Estados Unidos eram um player cujo poder político estava em ascensão. Isso porque os Estados Unidos eram o único país com condições econômico-financeiras de auxiliar a reconstrução da Europa, além de ter sido fundamental para a vitória aliada no conflito e ser a maior - praticamente única - fonte de comércio disposta a abastecer uma Europa destruída e quase sem produção de bens que não os bélico-militares. Nesse sentido, o cálculo racional francês necessariamente envolvia a concessão à determinadas demandas norte-americanas - no caso, o apoio à criação da Liga - com o intuito de receber apoio político e econômico de modo a manter a França como potência dentro do sistema internacional, fato que tinha sido ameaçado devido aos anos de guerra.

Esse cenário demonstra quão precário era o sistema de segurança coletiva no qual a Liga deveria se pautar e como essa ideia não fazia parte verdadeiramente da política que a França pretendia empreender nos anos subseqüentes. Durante todos os debates, portanto, a segurança coletiva se mostrava extremamente desinteressante para a França, cujos únicos objetivos eram a contenção militar germânica e a manutenção de seu status de potência por meio da ampliação de seu poder relativo e da instrumentalização da instituição política em questão. Entretanto, ao final das negociações, a delegação francesa já estava disposta a assinar os termos do Tratado visando a manter as alianças e garantir o apoio estadunidense 
aos interesses franceses na Europa. Isso mostra que ao longo do desenvolvimento da Liga das Nações, a instituição foi sendo abordada, cada vez mais, a partir de um caráter utilitarista e instrumental.

\section{A Política Externa do Reino Unido}

A delegação inglesa, por sua vez, possuía grandes afinidades com as políticas dos EUA, tendo em vista que ambas queriam evitar uma nova guerra a qualquer custo e o Reino Unido estava disposto a corroborar a criação de uma possível instituição voltada, majoritariamente, para a prevenção de conflitos. Contudo, divergências entre essas delegações eram visíveis no que diz respeito ao projeto idealista de Wilson (Egerton, 1974, p.420-421). Além disso, é válido notar que, ainda que o Estado inglês cogitasse a existência de uma nova instituição internacional, eles o faziam a partir da ótica instrumental de garantir a sobrevivência, preservar a influência e aumentar o poder político a partir desse novo mecanismo burocrático; a Liga das Nações nunca moldou, alterou ou sequer influenciou as preferências governamentais inglesas no que tange aos interesses nacionais, ela apenas foi parte das negociações como um elemento de barganha entre as delegações com o objetivo de assegurar interesses mais prementes.

A Inglaterra defendia uma visão mais simplista do que deveria ser a Liga das Nações e seu principal objetivo era a salvaguarda da supremacia comercial e do império britânico, após o restabelecimento das condições econômicas britânicas com a reconstrução do país. Para garantir este império e para manter o Reino Unido como ator principal na política 
internacional, era preciso que ele continuasse a ser a potência marítima hegemônica de antes - mesmo que a primeira guerra tivesse se mostrado muito custosa -, tendo em vista que o controle dos mares gerava um poder político proveniente da regulação do comércio internacional e, frequentemente, dos recursos naturais disponíveis nas colônias britânicas, fazendo com que o Reino Unido tivesse muita influência política no cotidiano dos outros Estados dependentes de seu comércio (MacMillan, 2004, p.47). E é nesse sentido que a Inglaterra tentava direcionar o desenho institucional da Liga, demonstrando, mais uma vez, interesses particulares no processo de criação do regime supracitado.

Ao debater sobre segurança coletiva na Conferência de Paz de Paris, a Inglaterra, opostamente a Wilson, seguia uma lógica realista, na qual acreditava que os Estados se pautariam exclusivamente em seus interesses nacionais e na luta pelo poder. Dessa maneira, por melhores que fossem as intenções da Liga, ela não mudaria esse tipo de comportamento. Alguns membros do governo britânico, como o secretário Sir Maurice Hankey, acreditavam que a segurança coletiva levaria a nação inglesa a uma falsa sensação de segurança, o que poderia acarretar futuramente em um desastre ainda maior. (Egerton, 1974, p.424-425)

Ao longo da Conferência, o Reino Unido adotou uma postura de tolerância em relação a algumas políticas tanto dos EUA quanto da França, para melhor garantir seu poder na Europa. A hegemonia comercial, traduzida pelo interesse na retomada econômica de todos os Estados, inclusive da Alemanha, estaria mais salvaguardada com o apoio dos Estados Unidos, que se daria em contrapartida ao apoio britânico à Liga das Nações, isto é, 
utilizando-a, assim como a França, como um instrumento de barganha diplomática. (Egerton, 1974, p.441)

É evidente, portanto, que a instituição nunca foi um objetivo em si, nem uma variável independente; sua criação estava sempre associada a concessões por parte do interlocutor na mesa de negociações, o que mostra como as ações estatais tomadas nesse momento foram pragmáticas e instrumentais. Ademais, é patente que a instituição, significativamente artificial e utilitária, em nada contribuiu para o aumento da estabilidade política regional, para a manutenção da paz e/ou impedimento da guerra (Mearsheimer, 1994/95, p. 44-46).

\section{A Liga das Nações}

Dessa maneira, é notório o papel secundário da formação da Liga como um projeto sólido e autônomo em relação a outros temas debatidos na Conferência (MacMillan, 2004, p.67). Nesse sentido, a Liga já nasceu sob a égide da desimportância, uma vez que nunca fez parte do cálculo racional das potências de então como elemento relevante para suas políticas auto-interessadas, para o aumento de poder relativo e/ou para a sobrevivência no sistema internacional. Esse projeto nunca foi, então, fruto de concessões feitas pela política externa de França e Reino Unido e não era, de fato, um objetivo buscado pelos países centrais do sistema, mas por indivíduos particulares com algum poder de agenda, o que acabou gerando seu fracasso. 
A teoria realista da estabilidade hegemônica advoga que os regimes ${ }^{4}$ devem ser sustentados por um poder central que tenha interesse e capacidade de promover os "bens públicos”, isto é, bens que não podem ser taxados, por exemplo, a segurança. Como garantir a disponibilidade desse tipo de bem é dispendioso e, por assim dizer, não lucrativo, é necessário a existência de um Estado com poderes superiores - condições econômicofinanceiras - e com motivação para oferecê-los. (Kindleberger, 1973, p.19-30)

Esse não era o caso do sistema internacional no fim da I Guerra Mundial. Os atores relevantes no cenário, as possíveis potências existentes então eram apenas os principais vencedores da I Guerra Mundial, ou seja, Estados Unidos, França e Reino Unido. Isso porque o quarto grande vencedor do conflito, a Itália, apesar de ter feito parte, durante a Conferência, do Conselho Supremo ${ }^{5}$, não desempenhava um papel político significativo no sistema internacional de então devido à sua recente unificação, ao seu pequeno império colonial e à sua participação de menor importância no conflito recém-findado.

França e Reino Unido, em contrapartida, que ainda eram as duas potências proeminentes no sistema internacional, principalmente devido a suas colônias e, no caso inglês, também a seu comércio, tampouco tinham interesse e/ou condições de se responsabilizar pela instituição criada. Na realidade, a ratificação de ambos os países ao Pacto da Liga nada

\footnotetext{
4 Esse termo é utilizado de maneira intercambiável com o termo “instituições” e “organizações” internacionais, baseado em Mearsheimer (1994/95, p. 8-9).

${ }^{5}$ O Conselho Supremo era um órgão informal que reunia, durante a Conferência, altos representantes de Estados Unidos, França, Itália, Japão e Reino Unido para discutir e chegar a conclusões acerca dos grandes temas da mesma sem enfrentar as dificuldades do debate incluindo todos os outros países participantes. Foi, em um segundo momento, substituído pelo Conselho dos Quatro, que incluía apenas os líderes dos quatro grandes vencedores do conflito presentes na Conferência (MacMillan, 2004, p. 65).
} 
mais foi do que um instrumento político para atingir objetivos maiores como as reparações alemãs, a redistribuição de territórios e de material militar e a aquisição de crédito frente à insistência do presidente norte-americano em consolidar seu projeto ideológico pessoal. (Trachtenberg, 1979, p.24-55)

Levando em conta que França e Reino Unido, como já exposto, não tinham interesses reais na Liga das Nações, mas apenas interesses temporários e que visavam a outros ganhos distintos da instituição em si, os Estados que compunham a Liga, de um modo geral, não prezavam pela sua continuidade, aplicabilidade e coerência com os princípios que deveriam norteá-la. Para agravar o cenário, o sistema internacional passava por um período de transição da hegemonia britânica imperante no século XIX à hegemonia norte-americana, que veio a se consolidar no pós-II Guerra.

Sendo assim, a ausência dos Estados Unidos não teria tanta importância como a literatura freqüentemente assevera, já que, após a I Guerra Mundial esse país ainda adotava uma postura absolutamente isolacionista e pouco interessada nos assuntos da Europa (Harvey, 2004, p. 38-48). Na realidade, antes do desfecho da II Guerra Mundial, os Estados Unidos ainda não haviam assumido plenamente seu papel de potência hegemônica mundial

(...) dadas as fortes correntes isolacionistas tanto na esquerda quanto na direita e um longo temor histórico aos envolvimentos externos como algo contrário a sua própria forma de governo, [dessa maneira,] os ímpetos imperiais foram ocasionais e escassos. (Harvey, 2004, p.47) 
A não ser pela posição particular e idealista de Wilson e seu desejo último de consolidar seus objetivos ideológicos (MacMillan, 2004, p. 11-26), os Estados Unidos ainda se insulavam na América sem assumir seu papel futuro de liderança na política internacional; e a evidência maior desse isolamento foi exatamante a recusa do senado norte-americano ao regime (Claude, 1981, p.372-377). Logo, os Estados Unidos ainda não tinham suplantado a hegemonia britânica nem o peso político francês no cenário europeu quando da criação da Liga e foi muito menos a sua recusa do que a displicência dessas duas potências que levaram a organização ao seu fim.

Sob essa perspectiva, a Liga certamente não alcançaria o sucesso em sua empreitada, uma vez que os Estados Unidos ainda não havia assumido seu papel de liderança mundial em 1919 e as potências vencedoras da Europa tinham pouca capacidade e nenhum interesse de manter um regime legalista-institucional para garantir a paz, mas sim um desejo concreto de retornar à dinâmica do Concerto Europeu do século anterior.

\section{Conclusão}

Após o desenvolvimento de nosso raciocínio argumentativo, e após a análise de todo o aparato teórico apresentado, concluímos que é uma grande falácia a enorme importância atribuída a não adesão dos Estados Unidos à instituição idealizada particularmente pelo presidente norte-americano Woodrow Wilson. Assim como todo evento ocorrido nas ciências humanas, o fracasso da Liga das Nações não se deve exclusivamente a um único 
fato e certamente a recusa do senado americano em participar do regime o enfraqueceu de algum modo.

Entretanto, verificamos a nossa hipótese de que a postura auto-interessada da França e do Reino Unido, em detrimento do bem comum identificado como a paz, durante as negociações na Conferência de Paris no pós-guerra, quando da elaboração do Tratado de Versalhes e, por conseguinte, do Pacto da Liga, foram aspectos ainda mais significativos para a posterior dissolução da instituição.

Chegamos a essa conclusão devido às evidências de que a criação da Liga em si já foi crucial para o insucesso da mesma, tendo em vista suas falhas e brechas jurídicas, seu mecanismo ineficaz na tentativa de ser democrático (Riggs \& Plano, 1994, p. 10-11) ${ }^{6}$, e, principalmente, a ausência de uma liderança hegemônica que assumisse o papel de garantir a existência do regime e os instrumentos de enforcement e de promoção da cooperação (Keohane, 1984, p. 18) ${ }^{7}$.

Sendo assim, corroboramos nossa hipótese de que a política externa auto-interessada da França e do Reino Unido durante a Conferência de uma maneira holística foram sine qua non para a frustração da perspectiva wilsoniana no contexto empírico. Esse elemento foi

\footnotetext{
${ }^{6}$ A aprovação de medidas tanto no Conselho quanto na Assembléia da Liga, deveriam ser aprovadas por uninimidade. Essa característica conferia maior igualdade entre os Estados, mas também dificultava enormemente a atuação da organização.

${ }^{7}$ A crença compartilhada entre o Neoliberalismo Institucional e o Realismo de que as instituições aumentam o fluxo de transações, aproximam diferentes áreas de comércio (issue-linkage), aumentam a disponibilidade de informação e diminuem os custos de transação; com o adendo do realismo de que esses benefícios devem necessariamente ser sustentados por uma hegemonia interessada e com capacidades para fazê-lo (Mearsheimer, 1994/95, p. 18).
} 
bem mais crucial do que as justificativas que costumam ser proferidas para a dissolução da Liga e, paradoxalmente, é bem menos abordado pelos teóricos de um modo geral, mostrando, assim, a lacuna da literatura existente.

Pretendemos, então, preencher esse lapso teórico e abrir espaço para estudos futuros mais aprofundados sobre o mesmo tema ou temas adjacentes, como a proposta wilsoniana universalista para a Liga das Nações em contraposição ao interesse britânico e inglês ao reestabelecimento do status quo ante bellum do Concerto Europeu ou, ao menos, de uma limitação geográfica da atuação da Liga na Europa. 


\section{Referências}

CLAUDE, Inis. Casual Commitment in International Relations. Political Science

Quarterly, v. 96, n. 3, Outono, 1981. Disponível em < http://www.jstor.org/pss/2150550>. Acesso em 02 nov 2008.

EGERTON, George W. The Lloyd George Government and the Creation of the League of Nations. The American Historical Review. v 79, n. 2, p. 419-444, abr. 1974. Disponível em <http://www.jstor.org/stable/1850330>. Acesso em 22 out 2008.

ENCYCLOPAEDIA BRITANNICA. Paris Peace Conference. Enclyclopaedia Britannica Online, 2008. Disponível em: <http://www.britannica.com/EBchecked/topic/443901/ParisPeace-Conference> . Acesso em: 2 nov 2008.

HERZ, Mônica; HOFFMANN, Andrea Ribeiro. Organizações Internacionais: História e Práticas. Rio de Janeiro: Campus, 2004.

HARVEY, David. O Novo Imperialismo. São Paulo: Edições Loyola, 2004.

HOBSBAWN, Eric. A Era dos Extremos: O Breve Século XX - 1914-1991. $2^{\text {a }}$ Ed. Rio de Janeiro: Companhia das Letras, 2007.

KEOHANE, Robert O. After Hegemony: Cooperation and Discord in the World Political Economy. Princeton, N.J.: Princeton University Press, 1984. IN: MEARSHEIMER, John J. The False Promise of International Institutions. International Security, v. 19, n. 3, p.549, Inverno, 1994/95. Massachusetts: The MIT Press. Disponível em $<$ http://links.jstor.org/sici?sici=01622889\%28199424\%2F199524\%2919\%3A3\%3C5\%3ATFPOII\%3E2.0.CO\%3B2-C.> Acesso em 22 de outubro de 2008.

KERGUENO, Aurelia. L'Engagement Francais dans le Processus d'Internationalisation des Droits de l'Homme. Memoire Online. Disponível em:

$<$ http://www.memoireonline.com/09/06/210/m_engagement-francais-internationalisationdroits-de-l-homme2.html>. Acesso em 02 de novembro de 2008.

KINDLEBERGER, Charles Poor. The World in Depression, 1929-1939. Berkeley : University of California Press, 1973.

KISSINGER, Henry. Diplomacy. Nova Iorque: Simon \& Schuster, 1994. 
MACMILLAN, Margaret Olwen. Paz em Paris, 1919: A Conferência de Paris e seu mister de encerrar a Grande Guerra. Rio de Janeiro: Nova Fronteira, 2004.

MEARSHEIMER, John J. The False Promise of International Institutions. International Security, v. 19, n. 3, p. 5-49, Inverno, 1994/95. Massachusetts: The MIT Press. Disponível em $<$ http://links.jstor.org/sici?sici=01622889\%28199424\%2F199524\%2919\%3A3\%3C5\%3ATFPOII\%3E2.0.CO\%3B2-C>. Acesso em 22 de outubro de 2008.

RIGGS, Robert C.; PLANO, Jack. C. The United Nations: International Organizations and World Politics. Belmont, CA: Wadsworth, 1994.

TRACHTENBERG, Marc. Reparation at the Paris Peace Conference. The Journal of Modern History. V. 51, n. 1, mar. 1979. Disponível em $<$ http://links.jstor.org/sici?sici=00222801\%28197903\%2951\%3A1\%3C24\%3ARATPPC\%3E2.0.CO\%3B2-Z>. Acesso em 03 nov 2008. 